\title{
Teaching Reform and Exploration in Compiling Principles Course for Application-Oriented Undergraduate Colleges
}

\author{
Peini Shang* \\ School of information engineering, Yulin University, Yulin, Shaanxi, China \\ 157724554@qq.com
}

Keywords: Compiling principles; Project of teaching; Reformation of teaching; Teaching model

\begin{abstract}
Compiling Principles is an important professional and foundation course in computer major. This paper studies the characteristics of the course of Compiling Principles, and the problems existing in the course teaching of Compiling Principles were analyzed. Aiming at the characteristics of computer major in application oriented universities, we have made a positive exploration of the teaching content, teaching methods and means, practice teaching system and so on. The teaching practice in recent years shows that the reform has aroused the students' learning interest, and has achieved good teaching results.
\end{abstract}

\section{Introduction}

Compiling Principles is a very important basic course for all kinds of computer and information class in Colleges and universities, and it is one of the compulsory subjects most graduate institutions to recruit graduate students. This course has many characteristics, such as theoretical abstraction, concept and algorithm. It can train students to master the basic theory, structure, design and implementation technology of the advanced programming language and compiler. On the one hand, it can help the application of undergraduate students to lay a solid theoretical foundation for future software development, on the other hand to enhance their programming capabilities and innovative ability. [1,2]

The problems existing in the course teaching of Compiling Principles were analyzed in this paper, and aiming at the characteristics of computer major in application oriented universities, we put forward the reform of the teaching mode of the course. The teaching practice in recent years shows that the reform has aroused the students' learning interest, and has achieved good teaching results.

\section{The Problems Existing in the Teaching of Compiling Principles}

Compilation principle of curriculum content has strong theoretical and practical, students in the learning process are abstract and complex algorithm, difficult to understand, therefore, compile principle is generally regarded as one of the most difficult, the most difficult course on learning in the teaching of computer majors.[3] Specific reasons are as follows:

In the existing materials, mostly from the basic theory and thought of compiling to tell the students feel too abstract, to complete construction of a compiler system is not an easy thing which not only need to have complete knowledge of the software and use the need to master the existing software tools and more importantly have rich experience to understand the hardware structure of the system and the function of the operating system. These for just finished basic knowledge of students to understand the degree of difficulty is quite large; [4,5]

For students, this course involves abstract and difficult to understand the theoretical knowledge, such as formal language and automata theory, grammar guidance theory, etc.;

This course contains many algorithms, the LL (1) analysis algorithm and a variety of LR (1) analysis algorithm, DFA simplification algorithm, calculation of flow equation algorithm, FIRST data collection and FOLLOW collection of the iterative algorithm is small. It is difficult for students to think deeply of algorithms [6,7];

Compiler size, it is not possible in a course of time to all the details are clear, the students of the 
logic of the compiler interface between the parts and some algorithm to achieve [4];

Under the new situation of students learning enthusiasm is not high, serious fear of hardship, in learning the great strength and perseverance is not enough. $[8,9]$

\section{Curriculum Teaching Content Reform}

The reform of the whole course system is to promote the whole course system, supplemented by the Compiling Principles. In the research of this topic, the topic group members first examine and analyze the internal relations between the courses. Make clear the relationship between the curriculum can be related to the curriculum and teaching links to form a system to reduce the content of the teaching content of the repeated enhancement of the overall effectiveness of the class to achieve reduction in efficiency.

Compilation principle is established to provide theoretical and practical basis in many prerequisites basis for subsequent courses. $\mathrm{C}$ language and PASCAL solve the definition of various grammatical units in language use and problems, provides the basis for the analysis of "Compiler Principle" in the grammatical units, small compiler programming provides a prerequisite.

A collection of related knowledge in Compilation Principle course and the direct use of the discussion of "discrete mathematics" theory, graph theory, logic reasoning, especially formal language and automaton theory is the main theoretical basis of Compiling Principles. So the members of the research group will be incorporated into the theory of automata in discrete mathematics teaching materials and teaching as the focus.

The algorithms involved in the course of Compiling Principles are many and complex. The reading and analysis of the algorithm should be solved in the course of algorithm. Therefore, in the teaching of algorithm, we should focus on the deep meaning of the algorithm, function and description methods, combined with examples, reasoning, time and space complexity analysis. So the algorithm teaching should run through the professional course. Because the compiler as the system software has strict requirements in performance, which makes it the algorithm used by the classic and efficient, and these algorithms, idea and implementation techniques can be widely used in the general software design and implementation. Therefore, the members of the project group in the process of teaching encourage students to try to compile the program in a variety of algorithms and techniques are applied to various application fields, so as to stimulate students' creative thinking, cultivating students' innovative ability and a solid foundation for the further study.

\section{Improve Teaching Methods and Teaching Methods}

Firstly, we can use the problem based teaching method, the problem of teaching is generally divided into four steps: the problem, guide the problem, solve the problem, the expansion of the problem. For example, in the analysis of the parser, we first put forward the problem to be solved, and then introduce the common methods of parsing, and finally guide the steps and process of parsing. In the process of guiding, it is difficult to solve the problems in the process of grammatical structure and the extension of the problem to the same kind of grammar in different grammar analyzer, so that students in the process of decomposition of the understanding and application.

Secondly, the establishment of multi angle, all-round three-dimensional teaching environment. The use of modern teaching methods, multimedia facilities, electronic teaching plans and other ways to achieve effective classroom time. In the traditional teaching mode theory requires a lot of writing on the blackboard, the teacher is busy, and students are busy taking notes, a class teacher students tired, tired, the students do not know the specific content. With the help of multimedia, the derivation of various algorithms at a glance, the teacher's focus on the principle of the algorithm to explain the logic of relations between the principles, the students are focused on understanding. Specific approach to provide students with all kinds of resources in the online teaching system. Such as CAI software library, teaching database, electronic library. To help students understand the content of classroom teaching.

Based on the Internet network and multimedia technology can be used as an auxiliary means. 
There is a discussion of learning mode, exploring learning mode, providing all kinds of resources in the network assisted teaching mode. In Internet can be achieved on the study, the traditional teaching mode, students in the learning process of the difficulties with the teacher couldn't face to face, then through the network the teacher can answer their questions. This model completely changed the state of passive acceptance of students in the traditional teaching process, so that students in a positive and active position, which can effectively stimulate students' learning interest and creativity. To this end, we built the "principle of compiling teaching website to collect complete compilation principle and technical documentation, this site includes assignments, answering, test content, we recommend to students as the second classroom learning.

Thirdly, improve the examination means. Examination is an important means to examine the effect of teaching. To this end, we develop a practical curriculum according to share strict assessment methods. According to the requirements of the teaching syllabus and the students' mastery of the course, we have compiled a set of advanced and perfect examination question bank, and set up the accurate and reasonable grading standard.

The examination results are divided into two major parts, the final examination results and major operating results. Final examination using a closed book examination, examination questions from the question bank to select, wide coverage, a reasonable degree of difficulty, the basic concepts and basic knowledge. The paper has the reference answer and standard for evaluation, take collective marking, assembly line, to be fair and impartial. The investigation of students' practical ability and comprehensive ability. The examination of the course can not only test the students' textbook knowledge, but also can test the students' ability to analyze and solve problems. After the examination is finished, we can write the examination paper analysis and the teaching effect in time according to the students' examination results, and put forward the suggestions to improve the teaching quality.

\section{Consummating Practice Teaching System}

Practice education is an important part of the innovative talent training system. Experimental education plays an irreplaceable role in improving students' comprehensive quality, cultivating students' scientific spirit and practical ability. "Compiler Principle" is one of the computer courses of close combination of theory and practice, its content has deep theoretical knowledge, and related technology is the practice of the theory, practice theory teaching and experiment class combination, develop their ability of combining theory with practice.

In the course of teaching, pay attention to the principle of the Compiling Principles and software development practice, and guide students to use the theory and method of compiling in software practice. The design theory of compiler principle can be applied not only to the compiler, and can be used for general software design: text editor, automatic typesetting, pattern recognition, automatic program verification and program debugging, automatic conversion between high-level language tools, communication protocol conversion, cross compiler technology, chip design etc..

\section{Summary}

The development of computer technology change rapidly, the social demand for computer professionals are subject to change, facing the new situation and new requirements, the teaching should not be immutable and frozen in the teaching, and only through the teaching contents and curriculum system reform, in order to cultivate has to meet the social needs, innovation ability, and high-quality talent. Curriculum theory, learning and teaching strategies. Teaching practice in recent years, in the aspects of teaching content, teaching methods and means, practice teaching system reform made the positive exploration, to better mobilize the students' interest in learning, in cultivating students' learning ability, practical ability and creative ability and engineering consciousness has made a beneficial attempt, made good teaching effect. 


\section{Acknowledgements}

This paper is a report of the research project of teaching reform in the Information Engineering Institute of Yulin University.

\section{References}

[1] Z.L. Jiang: The realization of basic subject ability in the teaching of compile principle, J. Computer Education. Vol. 16(2007) No.1, p.28-30. (In Chinese)

[2] L. Gao: Exploration of teaching innovation of compile principle based on code of software project teams, J. Science \& Technology Information. Vol. 12(2008) No.2, p.19-89. (In Chinese)

[3] T. Wang, J.M. Li, H.P. Zhou: The study of cultivating computing thinking in the teaching of compile principle, J. Computer Education. Vol. 13(2009) No.21, p.11-13. (In Chinese)

[4] Z.L.Luo. Teaching reform practice and exploration of digital signal processing course. Educational Review. 2015

[5] Y.P.Zhong, Y.J.Guo, X.Y.Luo. Application of Problem-Based Learning mode in nursing practice student teaching. 2015 7th International Conference on Information Technology in Medicine and Education (ITME). 2015

[6] T.Wiktorski, T.Hacker, R.A.Hansen, G.Rodgers. Experience with Problem-Based Learning in a hybrid classroom. 2015 IEEE 7th International Conference on Cloud Computing Technology and Science. 2015

[7] Y.P.Huang. Exploration on the construction of digital signal processing high-quality curriculum. Education and Vocation. 2014

[8] S.Santos, G.Alexandre, A.Rodrigues. Applying PBL in project management education: A case study of an undergraduate course. IEEEFrontiers in Education Conference. 2015

[9] National Outline for Medium-and Long-Term Educational Reform and Development (2010-2020). 